\title{
A Case of Cytomegalovirus-Induced Arthritis after Lymphocyte-Depleting Therapy for Kidney Allograft Rejection
}

\author{
Richard Fuquay $^{1 *}$, James Eric Cooper ${ }^{2}$ \\ ${ }^{1}$ Health Science Center Division of Renal Diseases and Hypertension, University of Colorado Denver, Aurora, USA \\ ${ }^{2}$ Health Science Center Division of Renal Diseases and Hypertension, Transplant Center, University of Colorado Denver, Aurora, \\ USA \\ Email: $\left\{{ }^{*}\right.$ Richard.Fuquay, James.Cooper $\} @$ ucdenver.edu
}

Received January 14, 2012; revised February 13, 2012; accepted February 23, 2012

\begin{abstract}
Cytomegalovirus viremia and tissue-invasive disease are common after kidney transplantation. Chemoprophylaxis has made substantial improvement in this clinical problem. Here we report a 29 -year-old woman who had kidney allograft rejection and received lymphocyte-depleting therapy. She presented with a new oligo-arthritis that led to 2 successive arthrocenteses. The etiology of the inflammation could not be determined initially. On the second arthrocentesis, a synovial fluid cytomegalovirus polymerase chain reaction test was positive. The patient responded to treatment with valganciclovir, had negative follow-up serum cytomegalovirus polymerase chain reaction tests, and experienced resolution of her joint inflammation. We review briefly the data for cytomegalovirus chemoprophylaxis, preemptive screening, and treatment recommendations.
\end{abstract}

Keywords: Cytomegalovirus (Mesh); Arthritis (Mesh); Kidney Transplantation (Mesh); Immunosuppression (Mesh); Chemoprevention (Mesh); Valganciclovir (Mesh)

\section{Case Report and Methods}

A 29-year-old woman with a history of ESRD due to vesico-ureteral reflux underwent living non-related donor kidney transplantation in January 2009. She was seropositive for cytomegalovirus (CMV) IgG antibodies and received a kidney from a CMV seropositive donor. She received 3 days of lymphocyte-depleting induction with thymoglobulin and was placed on maintenance immunosuppression consisting of tacrolimus, myfortic, and prednisone, as well as valganciclovir $450 \mathrm{mg}$ per day for chemoprophylaxis against CMV disease. Serum creatinine (SCr) fell to a nadir of $1.0 \mathrm{mg} / \mathrm{dL}$ (normal, 0.4 to $1.2 \mathrm{mg} / \mathrm{dL}$ ) following transplant. The patient presented with a $\mathrm{SCr}$ of $4.15 \mathrm{mg} / \mathrm{dL}$ at 4 months and 2 weeks after her transplant surgery. (The patient later admitted to medication nonadherence.) Valganciclovir was stopped due to deteriorating graft function.

On day 1 of her course, the patient was admitted for renal allograft biopsy which revealed Banff IIa rejection with severe interstitial inflammation, focal endothelialitis, and negative staining for C4d. She began a course of lymphocyte-depleting therapy with thymo-

${ }^{*}$ Corresponding author. globulin $1.5 \mathrm{mg} / \mathrm{kg}$ per day, which was changed to muromonab-CD3 (OKT3) $5 \mathrm{mg}$ per day after 3 days due to development of a rash. She received 9 total doses of lymphocyte-depleting therapy for acute rejection, resulting in a new baseline $\mathrm{SCr}$ of $2.8 \mathrm{mg} / \mathrm{dL}$.

On day 8 of her course, she experienced abrupt onset of bilateral knee and hip pain, severely limiting her ability to walk. She was afebrile, but had warmth and effusion most pronounced over the right knee. There was no rash. The plasma white blood cell (WBC) count was 25,800 cells $/ \mu \mathrm{L}$ (normal, 4.0 to 11.1 cells $/ \mu \mathrm{L}$ ). Arthrocentesis of the right knee was performed; gram stain revealed no organisms, but heavy neutrophils. The synovial fluid WBC count was 48,400 cells/ $\mu \mathrm{L}$ (normal, $<200$ cells $/ \mu \mathrm{L})$. The fluid was turbid, and there were no crystals.

Cultures of synovial fluid and blood did not grow any organisms. The patient was treated empirically with intravenous ertapenem $500 \mathrm{mg}$ per day and vancomycin $750 \mathrm{mg}$ per day, for a total course of 14 days. Her knee pain slowly improved, and she was able to resume ambulation. She was discharged on day 11 of her course.

On day 17 of her course, the patient was readmitted 
with a SCr of $3.9 \mathrm{mg} / \mathrm{dL}$. Repeat allograft biopsy showed Banff $\mathrm{Ib}$ rejection with mild interstitial fibrosis and tubular atrophy, resulting in 6 more doses of OKT3. SCr fell to a new baseline of $2.9-3.3 \mathrm{mg} / \mathrm{dL}$.

On day 28 of her course, the patient was readmitted for knee pain. A repeat arthrocentesis of the right knee was performed, and the rheumatology consult service saw the patient. The leading diagnoses under consideration were serum sickness reaction, palindromic rheumatoid arthritis, and seronegative spondyloarthropathy. A CMV polymerase chain reaction (PCR) was ordered on the synovial fluid. The synovial fluid CMV PCR was positive at 1660 copies $/ \mathrm{mL}$ (nl, $<100$ copies $/ \mathrm{mL}$ ). On day 30 , the serum CMV and Epstein-Barr virus (EBV) PCR tests were positive at 113,500 and 71,950 copies $/ \mathrm{mL}$, respectively (CMV and EBV PCR normal, $<100$ copies/mL). HSV PCR was negative. Other negative serologies included $\mathrm{HIV}$, hepatitis B, hepatitis C, and parvovirus IgM.

After the second arthrocentesis, the patient was started on renally-adjusted valganciclovir at $450 \mathrm{mg}$ every other day. She experienced rapid improvement in her joint pain and swelling. The patient completed a three-month course of valganciclovir (adjusted for changes in renal function). She continues to have intermittent pain in the right knee, but there is no warmth or swelling. Subsequent serum PCR screens for CMV showed a nearly 10 -fold reduction at 12 days after initiation of valganciclovir, and undetectable levels 48 and 52 days after initiation of treatment. EBV PCR was repeated 6 weeks after start of valganciclovir and found to be negative.

\section{Discussion}

We present here a case of CMV-induced acute oligoarthritis after lymphocyte-depleting immunosuppression for acute renal allograft rejection. CMV infection is a major cause of morbidity and mortality in the renal transplant population, and CMV pneumonitis was a ma- jor cause of death in renal transplant recipients before the availability of chemoprophylaxis [1]. In addition, CMV infection and disease have been found to be associated with acute rejection as well as overall mortality in kidney transplant recipients [2].

Arthritis is a rare manifestation of CMV disease, which to our knowledge has only been described in two renal transplant recipients $[3,4]$ and one bone marrow transplant recipient [5]. Of the two renal transplant patients with CMV arthritis, the earlier patient died without any direct treatment of the CMV disease in 1978. The later patient received first intravenous, and then oral, ganciclovir with resolution of the infection in 1999. Both had synovial fluid aspirations with neutrophilic predominance. The differential diagnosis of acute arthritis in immunocompromised hosts includes, but is not limited to, infectious diseases, metabolic disorders such as gout, connective tissue diseases, and drug reactions including serum sickness. Additionally, idiopathic transudative effusions have been described in a case series of 37 kidney transplant recipients at Indiana University that had 11 cases of arthritis with effusion. Sampling revealed that all effusions were transudative, free of crystals, and had an average WBC count of 28 cells/uL [6]. The differential diagnosis of post-transplant arthralgia is presented in Table 1.

To our knowledge, this case is the first to describe successful treatment of CMV-induced arthritis with valganciclovir, the orally available prodrug of ganciclovir. Valganciclovir has an oral bioavailability of $70 \%$, compared to $7 \%$ for ganciclovir [10]. A study by Asberg, et al compared the efficacy of oral valganciclovir to intravenous ganciclovir in 321 solid organ transplant recipients with tissue-invasive CMV disease [11]. Patients were randomized to receive 21 days of either $900 \mathrm{mg}$ oral valganciclovir twice daily or $5 \mathrm{mg} / \mathrm{kg}$ intravenous ganciclovir twice daily, followed by 49 days of valganci-

Table 1. Differential diagnosis of arthritis in a renal transplant patient.

\begin{tabular}{|c|c|c|}
\hline Etiology of post-transplant arthralgia: & Synovial fluid characteristics $[7,8]$ & Clinical notes \\
\hline $\begin{array}{l}\text { Septic (bacterial, and rarely viral, fungal, or } \\
\text { spirochetal) }\end{array}$ & $\begin{array}{l}10,000 \text { to } 100,000 \mathrm{wbc} / \mu \mathrm{L} ;>90 \% \\
\text { neutrophils; opaque to purulent }\end{array}$ & $\begin{array}{l}\text { Culture sensitivities vary with bacterial } \\
\text { organism; other infections require PCR or } \\
\text { special culture techniques }\end{array}$ \\
\hline Serum sickness & $\begin{array}{l}2000 \text { to } 75,000 \mathrm{wbc} / \mu \mathrm{L} ;>50 \% \\
\text { neutrophils; yellow to opaque }\end{array}$ & $\begin{array}{l}\text { Fever and rash accompany polyarthralgias } 1-2 \\
\text { weeks after exposure; caused by immune } \\
\text { complex deposition and complement activation }\end{array}$ \\
\hline Metabolic/crystalline (gout and pseudogout) & $\begin{array}{l}>3000 \mathrm{wbc} / \mu \mathrm{L} ;<50 \% \text { neutrophils; yellow to } \\
\text { opaque }\end{array}$ & $\begin{array}{l}\text { Cyclosporine impairs tubular excretion of uric } \\
\text { acid; in one study it caused gout in } 24 \% \text { of renal } \\
\text { transplant patients [9] }\end{array}$ \\
\hline Autoimmune (RA, lupus) & $\begin{array}{l}2,000 \text { to } 75,000 \mathrm{wbc} / \mu \mathrm{L} ;>50 \% \text { neutrophils; } \\
\text { yellow to opaque }\end{array}$ & $\begin{array}{l}\text { Diagnosis based on American College of } \\
\text { Rheumatology }\end{array}$ \\
\hline Non-inflammatory & $\begin{array}{l}<2000 \mathrm{wbc} / \mu \mathrm{L} ;<75 \% \text { neutrophils; yellow } \\
+/- \text { bloody }\end{array}$ & Consider trauma, OA \\
\hline
\end{tabular}


clovir therapy. At one year of follow up, rates of CMV recurrence were similar between groups $(14.8 \%$ and $15.5 \%$ for valganciclovir and ganciclovir groups, respectively, $\mathrm{p}=0.89$ ), as was patient survival and renal function.

This case highlights the importance of CMV chemoprophylaxis in heavily immunosuppressed patients. In this case, induction therapy was followed by chemoprophylaxis, but not subsequent courses of lymphocyte-depleting therapy for acute rejection, which led to a complication. Induction therapy or treatment of rejection with lymphocyte-depleting therapy raises the risk of CMV infection and disease. In one study, adding OKT3 treatment as induction therapy raised the incidence of CMV disease from $21 \%$ to $59 \%$ [23]. USRDS data have shown that recipients of CMV seropositive kidneys who do not receive prophylaxis have increased rates of CMV disease, allograft loss, and healthcare costs [12]. A recent Cochrane review found that prophylaxis for high risk patients reduces CMV infection, disease, and mortality in solidorgan transplant recipients by $39 \%, 58 \%$ and $37 \%$, respectively [13].

In this patient, CMV prophylaxis was withheld in the days following lymphocyte-depleting therapy due to concerns for side effects related to the patient's fluctuating renal function. Valganciclovir is known to cause anemia and leucopenia, but in severe cases involving improper dosing, fatalities have been reported [14]. In-vitro studies have shown that ganciclovir inhibits T-lymphocyte activation and proliferation at therapeutic concentrations [15].

The patient may have benefited from a preemptive screening strategy, which has been recommended as an alternative to universal prophylaxis in kidney transplant recipients at risk for CMV infection [16,17]. While prophylaxis has been associated with superior graft and patient survival $[18,19]$, as well as cost and quality of life benefits [20] compared to a preemptive strategy, the latter may be appropriate for patients at risk for CMV disease with contraindications to oral valganciclovir therapy $[17,21]$. In such an approach, monitoring of the serum CMV PCR is conducted at regular intervals (often weekly) to detect infections before tissue-invasive disease results [17]. Most CMV infections occur in the first few months after transplantation, or the first few months after CMV prophylaxis is stopped [22].

Treatment of CMV disease usually includes stopping lymphocyte-depleting therapy, reducing the dose of other immunosuppressive medications, and instituting antiviral therapy $[14,17]$. During treatment, the PCR is followed to verify that the virus is responding to the drug. In rare cases, primarily occurring in donor-positive to recipient-negative transplants, there have been antiviral-resistant CMV strains, with reported adverse outcomes [14,
17].

This case has some notable limitations. No effort was made to establish a histologic diagnosis or conduct immunofluorescence, as the patient improved briskly with valganciclovir. Additionally, it is impossible to definitively exclude culture-negative septic arthritis, a transient EBV mononucleosis, or systemic CMV viremia that "overflowed" into the joints. However, the patient's monoarticular pain, joint effusion, and the positive synovial fluid PCR indicate that the synovium was a focus (if not the only focus) of viral replication. Furthermore, the synovial fluid characteristics such as neutrophilic predominance are consistent with previous biopsy-proven cases of CMV arthritis. Serum sickness was unlikely based on the asymmetry, severity, and rapidity of the arthritis, the lack of rash or fever, and recurrence of symptoms without further drug exposure. Though the CMV PCR was not impressively high, we believe that may have to do with acquisition and handling; CMV is the best explanation for the clinical scenario.

In summary, we have reported a case of CMV-induced oligo-arthritis that followed aggressive immunosuppression for treatment of acute rejection of a kidney allograft. This disease may have been prevented, or diagnosed earlier, through the use of chemoprophylaxis or preemptive screening. Oral valganciclovir is an effective treatment for CMV disease, and other treatment considerations were reviewed.

\section{Author Contributions}

Richard Fuquay and James Cooper participated in the preparation of the manuscript.

\section{REFERENCES}

[1] C. N. Kotton, "Management of Cytomegalovirus Infection in Solid Organ Transplantation," Nature Reviews Nephrology, Vol. 6, 2010, pp. 711-721. doi:10.1038/nrneph.2010.141

[2] S. Sagedal, A. Hartmann, K. P. Nordal, K. Osnes, T. Leivestad, A. Foss, M. Degré, P. Fauchald and H. Rollag, "Impact of Early Cytomegalovirus Infection and Disease on Long-Term Recipient and Kidney Graft Survival," Kidney International, Vol. 66, 2004, pp. 329-337. doi:10.1111/j.1523-1755.2004.00735.x

[3] C. Contamin, J. P. Brion, F. Bayle, P. Morand, M. Peo'ch and P. Vialtel, "A Case of Arthritis Caused by Cytomegalovirus after Kidney Transplantation," Transplant Infectious Disease, Vol. 6, No. 2, 2004, pp. 87-89. doi:10.1111/j.1399-3062.2004.00052.x

[4] H. M. Friedman, T. Pincus, P. Gibilisco, D. Baker, J. P. Glazer, S. A. Plotkin and H. R. Schumacher, “Acute Monoarticular Arthritis Caused by Herpes Simplex Virus and Cytomegalovirus," The American Journal of Medicine, Vol. 69, No. 2, 1980, pp. 241-247. 


\section{doi:10.1016/0002-9343(80)90384-8}

[5] L. J. Burns and R. D. Gingrich, "Cytomegalovirus Infection Presenting as Polyarticular Arthritis Following Autologous BMT," Bone Marrow Transplant, Vol. 11, No. 1, 1993, pp. 77-79.

[6] J. D. MacFarlane, R. S. Filo and K. D. Brandt, "Joint Effusions after Kidney Transplantation," Arthritis \& Rheumatism, Vol. 22, No. 2, 1979, pp. 164-169. doi:10.1002/art.1780220209

[7] J. J. Cush and P. E. Lipsky, "Approach to Articular and Musculoskeletal Disorders," In: D. L. Longo, D. L. Kasper, J. L. Jameson, A. S. Fauci and S. L. Hauser, Eds., Harrison's Principles of Internal Medicine, McGraw-Hill, New York, 2012.

[8] S. J. McPhee and M. Papadakis, "Current Medical Diagnosis and Treatment," 51st Edition, McGraw-Hill Medical, New York, 2010.

[9] T. C. Noordzij, K. M. L. Leunissen and J. P. Van Hooff, "Renal Handling of Urate and the Incidence of Gouty Arthritis during Cyclosporine and Diuretic Use," Transplantation, Vol. 52, No. 1, 1991, pp. 64-67. doi:10.1097/00007890-199107000-00013

[10] C. E. Chamberlain, S. R. Penzak, R. M. Alfaro, R. Wesley, C. E. Daniels, D. Hale, A. D. Kirk and R. B. Mannon, "Pharmacokinetics of Low and Maintenance Dose Valganciclovir in Kidney Transplant Recipients," American Journal of Transplantion, Vol. 8, No. 6, 2008, pp. 12971302. doi:10.1111/j.1600-6143.2008.02220.x

[11] A. Asberg, A. Humar, H. Rollag, A. G. Jardine, H. Mouas, M. D. Pescovitz, D. Sgarabotto, M. Tuncer, I. L. Noronha and A. Hartmann, "Oral Valganciclovir Is Noninferior to Intravenous Ganciclovir for the Treatment of Cytomegalovirus Disease in Solid Organ Transplant Recipients," American Journal of Transplantation, Vol. 7, No. 9, 2007, pp. 2106-2113.

doi:10.1111/j.1600-6143.2007.01910.x

[12] M. A. Schnitzler, J. A. Lowell, K. L. Hardinger, S. B. Boxerman, T. C. Bailey and D. C. Brennan, "The Association of Cytomegalovirus Sero-Pairing with Outcomes and Costs Following Cadaveric Renal Transplantation Prior to the Introduction of Oral Ganciclovir CMV Prophylaxis," American Journal of Transplantation, Vol. 3, No. 4, 2003, 445-451. doi:10.1034/j.1600-6143.2003.00069.x

[13] E. M. Hodson, C. A. Jones, A. C. Webster, G. F. Strippoli, P. G. Barclay, K. Kable, D. Vimalachandra and J. C. Craig, "Antiviral Medications to Prevent Cytomegalovirus Disease and Early Death in Recipients of Solid-Organ Transplants: A Systematic Review of Randomised Controlled Trials," The Lancet, Vol. 365, No. 9477, 2005, pp. 2105-2115. doi:10.1016/S0140-6736(05)66553-1

[14] A. Asberg, A. Humar, A. G. Jardine, H. Rollag, M. D. Pescovitz, H. Mouas, A. Bignamini, H. Töz, I. Dittmer, M. Montejo and A. Hartmann, "Long-Term Outcomes of CMV Disease Treatment with Valganciclovir versus IV Ganciclovir in Solid Organ Transplant Recipients," American Journal of Transplantation, Vol. 9, No. 5, 2009, pp. 1205-
1213. doi:10.1111/j.1600-6143.2009.02617.x

[15] M. Battiwalla, Y. Wu, R. P. S. Bajwa, M. Radovic, N. G. Almyroudis, B. H. Segal, P. K. Wallace, R. Nakamura, S. Padmanabhan, T. Hahn and P. L. McCarthy, "Ganciclovir inhibits Lymphocyte Proliferation by Impairing DNA Synthesis," Biology of Blood and Marrow Transplantion, Vol. 13, No. 7, 2007, pp. 765-770. doi:10.1016/j.bbmt.2007.03.009

[16] J. A. Khoury, G. A. Storch, D. L. Bohl, R. M. Schuessler, S. M. Torrence, M. Lockwood, M. Gaudreault-Keener, M. J. Koch, B. W. Miller, K. L. Hardinger, M. A. Schnitzler and D. C. Brennan, "Prophylactic versus Preemptive Oral Valganciclovir for the Management of Cytomegalovirus Infection in Adult Renal Transplant Cecipients," American Journal of Transplantation, Vol. 6, No. 9, 2006, pp. 2134-2143. doi:10.1111/j.1600-6143.2006.01413.x

[17] C. N. Kotton, D. Kumar, A. M. Caliendo, A. Asberg, S. Chou, D. R. Snydman, U. Allen and A. Humar, "International Consensus Guidelines on the Management of $\mathrm{Cy}$ tomegalovirus in Solid Organ Transplantation," Transplantation, Vol. 89, No. 7, 2010, pp. 779-795. doi:10.1097/TP.0b013e3181cee42f

[18] V. Kliem, L. Fricke, T. Wollbrink, M. Burg, J. Radermacher and F. Rohde, "Improvement in Long-Term Renal Graft Survival due to CMV Prophylaxis with Oral Ganciclovir: Results of a Randomized Clinical Trial," American Journal of Transplantation, Vol. 8, No. 5, 2008, pp. 975983. doi:10.1111/j.1600-6143.2007.02133.x

[19] L. N. Small, J. Lau and D. R. Snydman, "Preventing Post-Organ Transplantation Cytomegalovirus Disease with Ganciclovir: A Meta-Analysis Comparing Prophylactic and Preemptive Therapies," Clinical Infectious Disease, Vol. 43, No. 7, 2006, pp. 869-880. doi:10.1086/507337

[20] F. L. Luan, M. Kommareddi and A. O. Ojo, "Universal Prophylaxis Is Cost Effective in Cytomegalovirus Serology-Positive Kidney Transplant Patients," Transplantation, Vol. 91, No. 2, 2011, pp. 237-244. doi:10.1097/TP.0b013e318200000c

[21] F. L. Luan, L. J. Stuckey, J. M. Park, D. Kaul, D. Cibrik and A. Ojo, "Six-Month Prophylaxis Is Cost Effective in Transplant Patients at High Risk for Cytomegalovirus Infection," Journal of American Society of Nephrology, Vol. 20, No. 11, 2009, pp. 2449-2458. doi:10.1681/ASN.2008111166

[22] D. C. Brennan, "Cytomegalovirus in Renal Transplantation," Journal of American Society of Nephrology, Vol. 12, No. 4, 2001, pp. 848-855.

[23] P. L. Hibberd, N. E. Tolkoff-Rubin, A. B. Cosimi, R. T. Schooley, D. Isaacson, M. Doran, A. Delvecchio, F. L. Delmonico, H. Auchincloss Jr. and R. H. Rubin, "Symptomatic Cytomegalovirus Disease in the Cytomegalovirus Antibody Seropositive Renal Transplant Recipient Treated with OKT31,2," Transplantation, Vol. 53, No. 1, 1992, pp. 68-72. doi:10.1097/00007890-199201000-00013 